\title{
On Development of Tourist Resources of Ancient Villages and Towns in Fuzhou, Jiangxi Province XIONG Wen-ping
}

Nanchang Normal University, Nanchang Jiangxi, China, 330029 Icshxwp@126.com

Key words: Fuzhou City, ancient villages and towns, resources integration, product upgrade

\begin{abstract}
Fuzhou City in Jiangxi Province boasts rich tourist resources of ancient villages and towns of high level and in large number, but such an advantage is yet to be transferred into the advantage in tourist economy. Starting with analyzing the features of tourist resources of ancient villages and towns in the city, the paper will probe into the significance of developing such resources, analyze the problems in tourism development in these ancient villages and towns and raise measures for developing tourist resources in ancient villages and towns in the city.
\end{abstract}

Generally, ancient villages refer to the villages formed during a certain historical period, featuring historical significance, cultural characteristics and artistic values [1]. Ancient villages and towns are creation of human beings during long-term adaptation to the environment, ancient culture and art of profundity for thousands of years, unique cultural and tourist resources and materialization of regional culture [2]. Tourism development in ancient villages and towns must focus on developing complementary tourism products, diversifying tourism products, popularizing the elegant historical and cultural connotations of ancient villages, and presenting intangible cultural connotation by tangible cultural means, so as to enhance the tourist charm and attraction of ancient villages [3]. Development of tourist resources in ancient villages and towns must stress coordinated development of regional natural and cultural environments under the guidance of the Scientific Outlook on Development, coordinate cultural values with moderate development of eco-tourism resources by creative thinking, strengthen cultural protection and take to a people-first and sustainable development path with overall balance [4]. Boasting a long history, outstanding talents and an agreeable environment, Fuzhou City features the magnificent Linchuan Culture. Ancient pioneers who started living there left hundreds of ancient towns and villages scattered amid mountains and waters, which show distinct architectural styles, accumulate rich cultural profundity and present abundant local flavors. These are both precious cultural heritage passed down by ancestors to Fuzhou people and exceptional and unrenewable tourist resources [5]. Fuzhou City in Jiangxi Province boasts rich tourist resources of ancient villages and towns of high level and in large number, but such an advantage is yet to be transferred into the advantage in tourist economy. Though tourism in ancient villages and towns has roused the attention of many scholars, it's hard to find researches into tourism in ancient villages and towns in Fuzhou, which is of rich tourist resources, so research in this connection shall be of significant theoretical and practical meaning.

\section{Characteristics of tourist resources of ancient villages and towns in Fuzhou City}

1. The resources of ancient villages are abundant of high level and in large number. Primary statistics show that there're more than 200 ancient villages in Fuzhou City, such as farming and reading villages represented by Liukeng Ancient Village in Le'an, Huping Ancient Village in Le'an and Shangchi Ancient Village in Dongxiang, and ancient village and towns with prosperous commerce and handicraft industry like Zhuqiao Ancient Village in Jinxi and Tangyin Ancient Town in Yihuang County. Among these resorts, Liukeng Ancient Village in Le'an County was listed as a National Key Cultural Relics Protection Unit; Liukeng Ancient Village in Le'an County and Zhuqiao Ancient Village in Jinxi County were entitled China's Historical and Cultural Village, and eight ancient villages and towns, including Wuzhang Village in Chongren County, Yiqian Town in 
Guangchang County and Zeng's Village in Jinxi County, were honored as Jiangxi Historical and Cultural Towns and Villages.

2. Relatively concentrated distribution of resources of high regionality. The tourist resources of ancient villages and towns in Fuzhou show a relatively concentrated distribution, mainly in the counties of Jinxi, Le'an, Guangchang and Yihuang, among which Jinxi stands out with the largest number of ancient villages and towns. It's easy to find in China's Traditional Village Catalog that Jinxi County boasts the largest number among all the counties mentioned above, followed by Yihuang County and Le'an County. And the catalog records 28 villages in Fuzhou City, including 21 in Jinxi, three in Yihuang, two in Le'an, one in Guangchang and one in Nancheng. In the Fourth Group of villages collected in the catalog, Jiangxi Province takes up 51, including 17 in Fuzhou City, among which 15 in Jinxi. Such a concentrated distribution is conducive to integrated development and protection of tourist resources of ancient villages and towns in Fuzhou City, especially in Jinxi County.

3. Relatively well-preserved resources of high value. The tourist resources of ancient villages and towns in Fuzhou City are in various types and large numbers, among which some are of high level with long standing, rich cultural connotation, grand and delicate architectural scale and good preservation, such as Zhuqiao Ancient Village and Huwan Ancient Village in Jinxi County, which are among the treasures on the land of Eastern Jiangxi in need of full exploration for their historical and cultural values so that further protection and development will follow to transfer their resource value into the advantage of tourist economy.

\section{Significance of Tourism Development in Ancient Villages and Towns in Fuzhou City}

1. To facilitate economic development of Fuzhou. Tourism concerns dining, lodging, traffic, sightseeing and shopping, thus it's of high integrity. Tourism development will drive the growth of many industries and boost cultural exchanges and foreign cooperation. Ancient villages and towns of Fuzhou City are mainly located in Jinxi County, Yihuang County and Le'an County, where tourism infrastructures and economic growth lag behind. Therefore, robust support to tourism development in ancient villages and towns will not only advance local economy and local infrastructure construction to bring about wealth but help inherit local culture and ensure positive social effects. Relevant departments of Fuzhou Government and at all administrative levels should make tourism development in ancient villages and towns a major project for propelling local economy and prosperity of local farmers.

2. To boost characteristic tourism and strengthen the competitiveness of Fuzhou tourism market. It's of great significance for Fuzhou to launch tourism development in ancient villages and towns, promote characteristic tourism development in Fuzhou, push forward tourism brand building in the city and establish its tourist image. Fuzhou boasts rich cultural tourism resources; in order to transfer such resources into the advantage of tourist economy, it's key to tourism development in Fuzhou to make it its goal to strengthen the city by cultural tourism, highlight characteristic tourism and establish its tourism brand. The development of ancient villages and towns at high level, in large number and of outstanding characteristics in Fuzhou City will be an important part of Fuzhou's tourism development to invigorate Fuzhou's tourism, establish its positive image and strengthen its market competitiveness.

3. To help with protection and development of tourist resources in ancient villages and towns in Fuzhou. Tourism in ancient villages and towns caters to nostalgia and creates good venues for people to explore the past, thus it's a tourism project of great prospect and unique charm. Possessing a large number of ancient villages and towns of large scales and long standings, Fuzhou should make these resources an important support for its tourism development in ancient villages and towns. Therefore, the city should enhance its protection and development of tourist resources of ancient villages and towns, strengthen development of tourism products, extend tourists' time of stay, meet tourists' demand for novelty and particularity, and broaden the tourism industrial chain. Tourist resources of ancient villages and towns in Fuzhou are unrenewable ones, making them very precious; however, due to people's lack of protection awareness in the past, some very valuable 
resources of ancient villages and towns didn't get well preserved but were severely damaged. Therefore, it's really urgent to strengthen protection and development of tourist resources in ancient villages and towns in Fuzhou, boost tourism development there, and thereby advance its economic growth.

\section{Problems in Developing Tourism in Ancient Villages and Towns}

1. Lack of protection awareness and shortage of investment. Subject to natural weathering, ancient villages and towns are in urgent need of protection after a long time of standing. People's lack of protection awareness has caused severe manmade damages to them: some are torn down as old buildings; some have become very shabby left vacant for long; some have lost their original value due to the use of modern materials and techniques for maintenance; and still some are used for other purposes like breeding industry. The traditional techniques and folk crafts applied to the buildings in ancient villages and towns are diversified so that their dwellings usually have valuable cultural heritages and intangible cultural heritages; however, some dwellers chose to trade their dwellings and building components for economic profits due to the lack of protection awareness.

Relics protection in ancient villages and towns needs a large amount of investment, but today the fund for such protection is mainly from government grant and seldom from social funds. Also, the owners of ancient dwellings cannot support the maintenance of their residences due to shortage of funds. Thus, the lack of investment somehow makes it hard to achieve protection and maintenance of ancient dwellings.

2. Monotonous tourism products and lack of strength in integrating tourism products. Fuzhou boasts a large number of celebrities and a nice eco-environment. Despite its expanding tourist market, Fuzhou is still void of ideal tourism development in ancient villages and towns, one of the most striking reasons for which is the lack of strength in integrating tourism products, especially in integrating the villages and towns with resources like cultural tourism, ecotourism and education tourism in Fuzhou, so that brand effect was not fully played and ancient villages and towns were not fully integrated with other tourism resources for complementary functions. And without satisfactory integration, tourism products can be easily monotonous in both content and form, thus lacking market competitiveness.

3. Absence of scientific and systematic tourism planning and broadened tourism industrial chain. Despite its rich resources of ancient villages and towns, Fuzhou hasn't formulated "Tourism Planning for Ancient Villages and Towns" yet; there's still no systematic guidance for the protection and development of ancient villages and towns in the city; there's no building of a product item system for ancient villages and towns, including planning of tourism product system, tourist projects and quality tourist routes for ancient villages and towns in Fuzhou; there's still no establishment of a tourism development guarantee system for ancient villages and towns in Fuzhou; and there's no building of organizations, development policies, publicity and marketing systems and investment and financing system for ancient villages and towns in Fuzhou. Tourism planning is a blueprint oriented to long-term development, involving planning in various aspects. All these show that the development of ancient village tourism in Fuzhou is in want of scientific, reasonable and standard practices.

Tourism involves dining, lodging, traffic, sightseeing and shopping, but tourism development in ancient villages and towns in Fuzhou is still in an extensive form that solely relies on the income of admission tickets. That's because the tourism-supporting infrastructures, such as regional tourist traffic, tourist lodging and tourist shopping engaged by ancient villages and towns in Fuzhou, are not complete enough to make tourists stay there for long. Such a one-day-tour tourism mode cannot well extend the tourism industrial chain in ancient villages and towns in Fuzhou or fulfill the overall appreciation of the tourist industry system in ancient villages and towns in Fuzhou.

4. Weak tourism publicity and marketing despite rich resources of ancient villages and towns in Fuzhou. Though Fuzhou owns rich resources of ancient villages and towns of rich cultural profundity, they've been unknown to people due to lack of tourism publicity and marketing. Entering an era of all-round informatization, tourism marketing and publicity in ancient villages and 
towns in Fuzhou are not innovative enough and their publicity resources are not well combined to form a full force. However, even the best products need marketing to get them sold. Ancient villages and towns in Fuzhou haven't combined their featured resources into a characteristic holistic image of ancient villages and towns in Fuzhou, built up a brand for them or present the image and brand to tourists. Due to conservative ideology and shortage of publicity funds, these villages and towns haven't taken various means and utilized all possible opportunities for publicity, so that it's hard to induce tourism spending spree in ancient villages and towns and there's no way to fully promote the popularity and positive image of these villages and towns, hence their lack of competitiveness in the tourist market.

\section{Measures for Developing Tourism in Ancient Villages and Towns in Fuzhou}

1. Focusing on quality products to drive all-round growth. Fuzhou boasts a large number of ancient villages and towns with relatively concentrated regional distribution. Tourism development in ancient villages and towns in Fuzhou should set priorities and catch the right focus. Planning should be made to identify quality products and establish the positive image of Fuzhou as home to ancient villages and towns, so that the city will stand out in the national tourism market of ancient villages and towns in fierce competition. Jinxi County in Fuzhou City has relatively large resources of ancient villages and towns, which are well preserved, in large scale and of high level. Therefore, tourism development in ancient villages and towns in Fuzhou should gather strengths of talents, funds and materials toward the county. With wider influence, Liukeng Ancient Village in Le'an and Zhuqiao Ancient Village in Jinxi can be bred into quality products. With focus on key regions and quality products and unified scientific planning, priority development should be encouraged to shape the positive image of ancient villages and towns in Fuzhou. On the basis that key regions and quality products win ideal benefits of tourism economy and good social reputation, quality products can drive the development of other projects and key regions can drive the development of tourist resources in other ancient villages and towns, so as to boost all-round development of tourist resources in ancient villages and towns in Fuzhou.

2. Realizing resources integration and upgrading products. The rapid growth of tourism and gradual increase of quality tourist projects in Fuzhou is offering increasing contributions to local economic growth. Fuzhou should attach importance to the integration of ancient villages and towns with other tourist resources in its tourism development, and fully demonstrate tourism in ancient villages and towns in Fuzhou through quality tourist routes and have them integrated into the holistic tourism of Fuzhou. The idea of independent development of ancient villages and towns should be updated to fully explore and integrate tourist resources and place equal emphasis on celebrity culture tourism and eco-tourism and tourism in ancient villages and towns, thus establishing reputations by the three types of tourism and build up a positive tourism image of Fuzhou. Also, complementary functions of tourism resources should be exerted based on characteristics of different tourist sources: not only should the cultural connotation of ancient villages and towns be explored to meet the sightseeing demand of tourists but activities should be launched to fully engage tourists and add to the fun of their experience. Therefore, it's necessary to integrate tourist attractions surrounding ancient villages and towns or build water game tourist areas, recreational ecotourism areas and holiday resorts beyond the protection zones of ancient villages and towns, and broaden the tourist functions of different scenic areas and spots.

3. Increasing investment and strengthening publicity and marketing. It's necessary to collect funds from all possible sources. On the one hand, non-government funds should be absorbed; on the other, more funds should be won from the government to ancient villages and towns for both their protection and development and tourism publicity. Due to conservative ideology and shortage of publicity funds, the image of ancient villages and towns in Fuzhou is still not clear-cut, without eye-catching characteristics. Many quality villages and towns are unknown to people except Liukeng Village in Le'an. Therefore, tourism publicity should be strengthened by utilizing the advantage of Fuzhou as a famous city of historical and cultural tourism. Fuzhou is the hometown of many renowned scholars like the playwright Tang Xianzu and the politician Wang Anshi, and 
Fuzhou also features an agreeable eco-environment. It still needs great efforts for tourism publicity and marketing in order to promote an all-round Fuzhou City to all tourists, with its long-standing Linchuan Culture, pleasant natural landscapes and large-scale resources of ancient villages and towns of high level and value. Compared with famous villages and towns like Wuzhen in Zhejiang and Wuyuan in Jiangxi, the ancient villages and towns in Fuzhou are far less known to the world. Many tourists come to Fuzhou for cultural resorts related to celebrities like Tang Xianzu and Wang Anshi or natural views like Dajue Mountain, but few pay attention to villages and towns like Huwan Village in Jinxi County and Huping Village in Le'an County, which is very regrettable in the information-based society today. Even the best products need marketing to get them sold. Ancient villages and towns in Fuzhou show characteristics and styles of the city, hence very important for its publicity and marketing. In the overall image design, the brand of ancient villages and towns of Fuzhou must be established an the individualities of ancient villages must be manifested. A tourism marketing plan of ancient villages and towns in Fuzhou must be carefully drawn and the characteristic resources of ancient villages and towns in the city should be integrated into an overall tourism image of these villages and towns, which should then be promoted to worldwide potential tourists. More input and stronger tourism publicity should be ensured and ideal media for publicity should be selected to promote ancient villages and towns; railway stations, coach stations, airports, subway stations, squares, main streets and bus stops with higher visitors flow should be chosen for publicity of ancient villages and towns; marketing and exhibition of tourism products should be made in major cities like Shanghai, Beijing and Guangzhou; and new media like WeChat and Weibo should be utilized for publicity. Cooperation can be launched with TV programs and films for shooting in scenic areas; photo contest for ancient villages and towns in Fuzhou can be given; int'l and national conferences can be staged to recommend ancient villages. In a word, tourism in ancient villages and towns in Fuzhou can be promoted with higher input and by all media or opportunities from various aspects and by all possible means, so as to lift the popularity and positive image of these villages and towns.

4. Making scientific and systematic planning and broadening tourism industrial chain. Scientific and systematic planning should be made to integrate the interests of the government, villagers, enterprises and tourists according to the stakeholder theory to focus their combined efforts on developing tourism in ancient villages and towns in the city. The planning should take into account economic benefit, social benefit, ecological protection and cultural protection, so that tourism development in ancient villages and towns in Fuzhou should be combined with the rise of tourist satisfaction. The most basic motivation for tourists to visit ancient villages is to experience the primitive rural environment, including their longing for the local characteristic ancient buildings, unique geomantic culture and featured folk custom, which show their original and complete pursuit of ancient villages. Therefore, during the development of ancient villages, it's necessary to coordinate the relations among planning, development and protection [6]. Sightseeing and participation of tourists should be combined and various resources should be pooled to build up a system of tourism products in ancient villages and towns in Fuzhou, tourism projects of ancient villages and towns in Fuzhou and quality tourist routes in ancient villages and towns in Fuzhou in order to form a complete system of products and projects of ancient villages and towns in Fuzhou, and establish and plan organizations, development policies, publicity and marketing system and investment and financing system for ancient villages and towns in Fuzhou in order to build up a complete tourism development guarantee system.

Tourism involves dining, lodging, traffic, sightseeing and shopping. Tourism infrastructures should be improved to make tourists stay there for long but not just go for one-day tour, thus he tourism industrial chain in ancient villages and towns in Fuzhou can be extended. Cultural creativity should be exerted to develop tourist goods in ancient villages and towns so as to rid them of an extensive form of tourism development that solely relies on the income of admission tickets, thus tourists can not only go for sightseeing but have further study, watch plays and shop there to realize the overall appreciation of the tourist industry system in ancient villages and towns in Fuzhou. 


\section{References:}

[1] Song Rui. Analysis and Forecast of China's Tourism Development in 2009 (First Edition) [M]. Beijing: Social Science Academic Press, 2008: 333-348.

[2] Sun Jing and Su Qin. Visual Impact of Tourism Development of Ancient Villages and Management - A case study of Hong Village in Xidi [J]. Human Geography, 2004 (08).

[3] Feng Shuhua. Thoughts about Tourism Development of Liukeng Ancient Village [J]. Jiangxi Social Sciences, 2002 (03).

[4] Ye Suwen. Measures for Coordinated Development of Tourist Economy Development and Cultural Values in Ancient Towns and Villages - A case study of Danshan Chishui Scenic Area in Shilin Ancient Village [J]. Ecological Economy, 2005 (10).

[5] Peng Minqun. Inheriting Cultural Treasures, Creating Tourism Brands and Guarding Spiritual Homeland - Investigation and Survey of Protection and Development of Ancient Towns and Villages by the Standing Committee of Fuzhou People's Congress[J]. Our Time, 2012 (11).

[6] Zhang Jianzhong, Liu Jiaming and Chai Da. Tourism Development in Ancient Villages from the Perspective of Cultural and Ecological Tourism - A case study of Hougou Ancient Village[J]. Economic Geography, 2015 (09). 